\title{
The power of Participatory Photography in ICTD programs: freedom to explore beyond images
}

\author{
Laura Gomez \\ University of Washington \\ lau.gomez88@gmail.com
}

\author{
Ricardo Gomez \\ University of Washington \\ rgomez@uw.edu
}

\author{
Sara Vannini \\ University of Washington \\ vanninis@uw.edu
}

\begin{abstract}
We discuss the contribution of participatory photography as a method to elicit lived experiences from the perspectives of participants, a valuable tool in ICTD research. Building on a participatory photography research project with Latino migrants in Seattle, Washington (USA) and at the US-Mexico border, we analyze the differences between descriptive accounts and interpretations of photographs offered by participants. By opening new possibilities for selfexpression, participatory photography offers a powerful tool that allows participants to add not just description but also context, representations, meanings, feelings and memories, among other interpretations. Different effects of the participants' photographs are also analyzed, to encourage further exploration of participatory photography in ICTD research.
\end{abstract}

\section{Introduction}

The field of Information and Communication for Development (ICTD) has extensively expressed the need for methods to help better understand the social use of ICT as experienced by communities in difficult contexts (such as poverty, lack of opportunities, marginalization, exclusion...) [1]

Researchers approach the elicitation and validation of lived experiences by participants in ICTD projects in different ways. We have been refining Fotohistorias, a methodology for participatory photography that is simple to use yet powerful to elicit lived experiences. Fotohistorias draws on a long tradition of participatory communication, visual communication, and ethnographic methods [2]-[4].

In this paper, we present an example of the use of Fotohistorias among undocumented migrants in the US: at the US-Mexico border, and in Seattle WA. Findings of the research about the experience of migration are reported elsewhere. We focus here on reflecting on the contributions of Fotohistorias as a method, and we seek to answer the two following questions:

1. What is the distance between the description of the visual content and the participants' interpretation of the images they created?

2. How do participants use participatory photography as part of the interview process?

In particular, we discuss the space between the visual content from a purely descriptive perspective, and participants' interpretations of the photographs they produce for the project. We suggest Fotohistorias is a powerful method that offers researchers in general, and in ICTD in particular, a lens into the lived experience of participants, a shortcut to the soul.

As reported by scholars, in fact, the field of ICTD could benefit from the use of participatory photography as the method as proven to increase empowerment of underserved communities, trigger participants' self-reflection and ideas for the design of information-related interventions, give them more voice, and bridge the researcher-researched gap. [1], [5], [6]

In the sections that follow we present a brief review of the literature followed by a description of the research methods, both of participatory photography for the creation of images and of visual methods for their analysis. We then present the salient findings of the analysis of 215 photos taken by Latino migrants both at the US-Mexico border and in Seattle, Washington, USA. We conclude with a discussion of the findings and implications for ICTD and social science research.

\section{Literature Review}

"A Picture is worth a 1000 words" is a popular English idiom that refers to the notion that a single image can convey its meaning effectively and without the need of words to describe it. However, when often true, in Participatory Photography images need the words of the participants to convey their meaning.

In Fotohistorias, we highlight the role of participatory photography as a tool that helps to elicit 
different types of responses, brings forward users' perspectives, shifts the balance of power-relationships (e.g.: between the researcher and the participant), and enhances participants' positive experiences with the research process. [7], [8]

Participatory photography has been well documented and successfully implemented as a technique that enables participants to share, and researchers to have access, to what in other studies based only on oral stimuli could remain unseen. As stressed by Sarah Pink, "meanings do not exist in photographs." $[9$, p. 92] According to Pink, it is the researchers' job to seek meaning in the way people use images to produce and represent what is not easily expressed by words. Thus, understanding how participants use images to constitute meaning and significance in a research process is of uttermost importance.

However, there is not much literature related to the analysis of the visual content of photographs used in participatory studies, particularly in the context of ICTD. Scholars so far have been focusing merely on either analyzing the interviews elicited with the use of photographs [10], performing general deductive content analyses on the visual material [5], or analyzing the messages of visual materials produced in highly visual literate contexts, where the phases of image production and editing is of uttermost importance. A few examples of this kind of studies refer to the relationships between the visual content and the explanation provided by participants about it: they are usually produced within communication, semiology or argumentation studies, and their main focus is not in understanding the specificities of this methodology as used with underserved communities. [11] In From photographs to findings, Sarah Drew \& Marilys Guillemin, affirm that "although the use of visual research is gaining increased acceptance, there remains a lack of attention directed to how to rigorously analyze visual images.”[12, p. 54] Both Drew \& Guillemin and Pauwels propose frameworks that allow the analysis of visual data. Pauwels [13] proposes an "Integrated Framework" which reflects and describes current practices of visual social scientists but emphasizes the analysis and interrelation of three themes: (i) origin and nature of visuals, (ii) research focus and design, and (iii) format and purpose. These themes correspond with the input, processing, and output phases of visual research projects, and distinguish between a "depiction" process and a "depicted" subject. Along with semiotic studies of the visual, this approach require more technical knowledge and awareness in image production than what it is normally expected in an ICTD project.
Meanwhile Drew \& Guillemin propose "interpretive engagement" as an analytical framework to describe the process of meaning-making in participant-generated photographs. "The framework involves five key elements, namely, the researcher, the participant, the image and the context of its production and the audience.'[12, p. 54] It also comprises three stages in the construction of meaning: meaningmaking through participant engagement, through researcher-driven engagement, and through recontextualizing. Stage 1 focuses on the participants, the images they have generated and its interpretation. Stage 2 involves "the researcher's reflections on participant explanations about the content, processes and contexts of their image production." $[12$, p. 60] And Stage 3 "provides an appropriate point to focus on the role of the audience and the process of engagement of the image/s with the audience, both anticipated and unanticipated.”[12, p. 64]

Banks meanwhile proposes a framework of visual analysis based on two kinds of narratives: an "internal" and an "external" one. The internal narrative of a picture is addressed by reporting a simple description of what the image is about (e.g.: a cat, a woman, a man with a gun; or, more interpretatively: my pet, his wife, a murder). The external narrative refers to the story constructed by answering to questions such as: who is the author of the picture, when it was taken and the reasons why it was taken?"'[14] Banks also stresses that the internal narrative does not necessarily need to correspond to the meaning that participants want to convey. On the contrary, in participatory studies the internal narrative is often quite distant from the external one, since the elements of the external narrative (the specific context participants live in) are the ones that shape its interpretations, and can be difficult to access by people that do not belong to the specific context. [15]

To this Drew \& Guillemin add that images "may have multiple meanings, that may change over time, or indeed remain relatively stable.”[12] For them, as well as for the other authors mentioned, meaning generation is a co-construction that involves the image, the participants, the researches and the context.

From a broader perspective, Participatory Photography is a technique based on the use of images during interviews, which allows for both enhancing understanding on a topic and gathering more and different data compared to methods that rely only on observation and oral communication [2]. Rose [16] defines photo-elicitation as a supporting method in the research process, where photos are normally used as further evidence or to better understand the context of research participants. 
Participatory photography was first introduced in 1957 by John Collier, who proposed the use of photo interviews to examine the quality of housing in Indigenous Communities in the Maritime Provinces of Canada and in New Mexico, among the others. Since, it has been used extensively in projects that involve vulnerable communities, as a way to access their worlds and give them a voice: marginalized groups "are normally not encouraged to share their perspectives, and photography gives them a means to do so."'[8]

The strength of this technique relies in the way humans respond to the stimulus of images. "The parts of the brain that process visual information are evolutionary older than the parts that process verbal information. Thus images evoke deeper elements of human consciousness than do words."[13] Also, the use of images has been proven helpful to let participants with a lower level of literacy (usually referring to underserved groups and children) express abstract and complicated concepts that they would encounter difficulties in expressing otherwise. [15][17] No previous knowledge of image production or visual literacy is required for participants to be able to participate through this technique. See: [10], [5]

\section{Research Methods}

\subsection{Fotohistorias: participatory photography}

We used Fotohistorias [8], [18] as a method to capture and understand migrants' life experiences at their most vulnerable times: while receiving services such as food and supplies at a shelter just minutes from the border in Nogales, Mexico, and while looking for jobs at a day labor dispatch center in Seattle, WA. In both places we worked in partnership with local organizations to gain entry, recruit participants, and conduct the research on site (in Nogales with El Comedor, a shelter run by the binational NGO Kino Border Initiative, and in Seattle with Casa Latina, a nonprofit job dispatch center that also serves the needs of immigrant day laborers and domestic workers).

The method is based participatory photography, and included providing participants with digital cameras and inviting them to take pictures of their daily lives to be discussed with the researchers. In Nogales, where migrants' lives were more transient, participants were given one day to keep the cameras and take their photos. In Seattle, where they were usually more established, they had one or two weeks to perform the task. Here, besides bringing back pictures taken with our cameras, they decided to complement their stories with pictures taken with their own devices, mostly mobile phones, or others they had previously posted on their Facebook profiles and that they found particularly representative of their life. All participants were interviewed by researchers on the stories, meanings and reasons behind the pictures that they brought back.

We conducted seven interviews with migrants in Nogales, Mexico, and fifteen in Seattle, Washington. Participants were recruited on a convenience sample and invited to participate in the research activities after being debriefed about ethical and safety measure about the pictures they could bring back.

All interviews were conducted in Spanish by Spanishspeaking members of the research team during summer 2014 (Nogales) and winter 2015 (Seattle). Interviews were translated, transcribed, and coded using the qualitative analysis software Dedoose. Pictures were renamed to match the interview they belonged to, and inserted into the interview transcripts to match their descriptions.

\subsection{Visual Analysis of selected photos}

In our study, we investigated the distance between the visual content and participants' interpretation of the images they created for Fotohistorias. Distance was here defined in terms of the internal and external narratives as described by Banks [14] (see section 2) and inspired by Pauwels' distinction between "depicted" and "depiction".[13] Besides, we analyzed how participants related to their own visual material when engaging in the interview process. We did not evaluate the norms, values and cultural traits that come into play in the production of an image, as Pauwels and other studies in semiotic suggest. [13], [19] We focused on how, in the current living situations of Fotohistorias, participants shaped the difference between what we defined as "description" and "interpretation" of the images. We define "description" as the content that appears in the image (e.g.: a car, a tree, a person, etc.) "Interpretation" refers, instead, to what the participant relates about the picture during the interview process. We also evaluated how the current place of living (transitioned or established,) as well as the shot type, the age and gender of the participants, could have influenced their meaning-making process.

For this analysis, we used the frameworks proposed by Pauwels and Drew \& Guillemin as starting points. [12], [13] From there, we set 6 different variables that enable us to measure the difference between the "description" and the "interpretation" of the photo by participants. Categories considered the difference in terms of adding context: (i.e.: adding details on what was was happening when the photo was taken); feelings (i.e.: adding details about how the participant felt about the image or when the image was taken); memories (i.e.: in case the photo reminded them of specific events); people (i.ie: details or 
identity of portrayed people); representation or meaning (i.e.: any metaphoric or symbolic use the photo, when it aimed to represent something that was not portrayed). A category "other" was also added. The categories used were not mutually exclusive, since, in many cases, participants' narrative could include long and complex explanations.

Photos were also classified according to some technical aspects, including the location where the study took place (Seattle or Nogales), shot type (close up, wide shot, landscape, medium shot and selfie), main subject in the photo (people, objects, landscapes or buildings), context (day or night, outdoors or indoors), and quality (dark or blurred). This was meant to understand whether certain patterns in the use of some effects as related to the interpretation provided could be the result of specific narrative choices, despite the fact that our participants were mostly not camera- and visual language-savvy. At the same time, we paid attention not to overcharge style elements with meaning: while we were very aware that some elements might have not been pre-conceived by our participants before taking their photos, we reckon that their interpretation of the elements that they created in their own stories was a valuable element to fully understand the methodology.

\section{Findings}

Intrigued by the many advantages that, according to scholars, participants-driven visual material production can bring to ICTD research (see: [5], [20], [21]) and by the interest in exploring more in depth the possibilities that this methodology carries along, we decided to take a closer look to the pictures used in Fotohistorias and analyze the distance between what is on an image and what the image mean to participants. In participatory photography, images aim to activate feelings, memories or stories as expressed by the participants.

We analyzed 215 photos resulting from Fotohistorias at the US-Mexico border and in Seattle. First, all photos were described by a member of the team according to their content and without referring

\begin{tabular}{|r|r|}
\hline \multicolumn{2}{|c|}{$\begin{array}{c}\text { Table 1: Aggregate types of interpretation of } \\
\text { photos by participants across sites }\end{array}$} \\
\hline Literal or Intrinsic & $29 \%$ \\
Add context & $29 \%$ \\
\hline Add representation or meaning & $13 \%$ \\
\hline Add feelings & $9 \%$ \\
\hline Add memories & $8 \%$ \\
Odhers & $7 \%$ \\
\hline Add people & $5 \%$ \\
\hline
\end{tabular}

to participants' interpretation of them. In a second moment, we compared each photo's description and interpretation, and we classified them according to the 6 categories of our framework: Literal or Intrinsic, Add context, Add feelings, Add memories, Add people, Add representation or meaning, and Other, which we ended up using mostly for the cases in which pictures completely differed from the participant interpretation of them. Finally, photos were categorized according to some technical aspects, as explained in 3.2.

Our findings point out two main kinds of relationships between the visual level of pictures and participants' description of them. On the one hand, participants' interpretation was used to add meaning to what the photo communicates. On the other hand, interpretation was related to some visual and technical elements of the photo itself, (e.g.: its quality and the presence of technology devices). Findings are presented following the two main research questions.

\subsection{In relation to $\mathrm{RQ1}$ : What is the distance between the description of the visual content and the participants' interpretation of the images they created?}

The results of our analysis show that, in Fotohistorias, the interpretations provided by participants were mainly of two kinds: they either reaffirmed the content of the photos, or they added details on context, representation, or feelings to them. The following sections will detail these two kinds of interpretation.

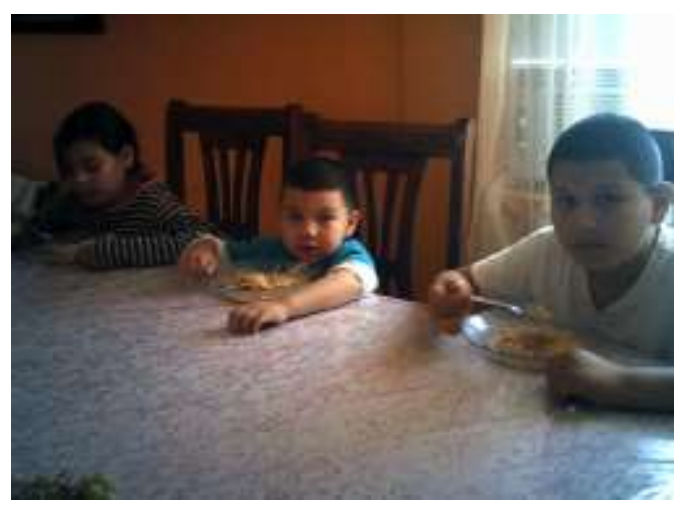

Figure 1: “Kids having lunch.” Photo by Armando 


\subsubsection{Literal or intrinsic interpretation}

As showed in Table 1, in most of the cases participants' interpretations were either literal (29\%) or they added context to the photos (29\%). The same pattern was observed in both locations. The predominance of photos that were described literally is explained by participants' desire to communicate. The image is their channel, their voice. In the following example participant's description reaffirms what is in the image (see Fig. 1).

"Those are my three kids sitting at the table having lunch." (Armando, Nogales)

Says the interviewee, after describing a typical day for him and his family. Family life is indeed important for him. Figure 2 presents another example of literal interpretation, but in this case it is followed by a rich account of the personal meanings it evokes.

"This is a picture of the two main parties of the U.S., the Republicans and the Democrats. I was not born in this country, but one day I would like to be able to vote. Maybe in 10 years, in 20 years. One day." (Juan, Seattle)

Here, the literal interpretation is not just a description of the visual. Juan presents also his hopes, to be able to vote one day, to be able to be part of his hosting country and participate in its political life. Finally, to express his opinion, and have his voice heard. Fotohistorias, a way to give participants a voice, is also the means where they express their need and hope for their voices to be stronger, and to be heard.

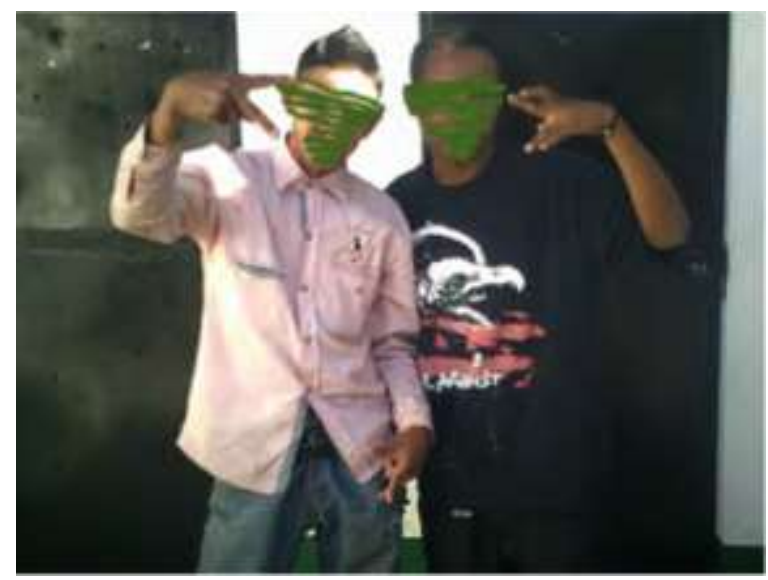

Figure 3: “Bathroom.” Photo by Chino

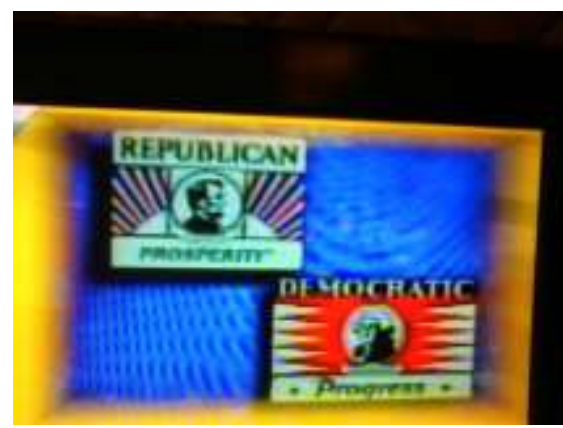

Figure 2: "Main Political Parties." Photo by Juan

\subsubsection{Interpretation adds context to description}

Participants who added contextual information to their interpretations of the pictures $(29 \%)$ used photos as a window to a bigger reality that had to be framed and further elaborated with words. The followings are two examples of interpretations that add context, one from Nogales and one from Seattle.

"This is in front of the bathrooms and we were waiting for the shower. It's really good to have these bathrooms and that we can take a shower." (Chino, Nogales, Figure 3)

"I felt like taking this photo that evening that I was eating for the first time at a buffet in the casino. In Mexico, when would you ever eat these luxury foods? Well, every once in a while

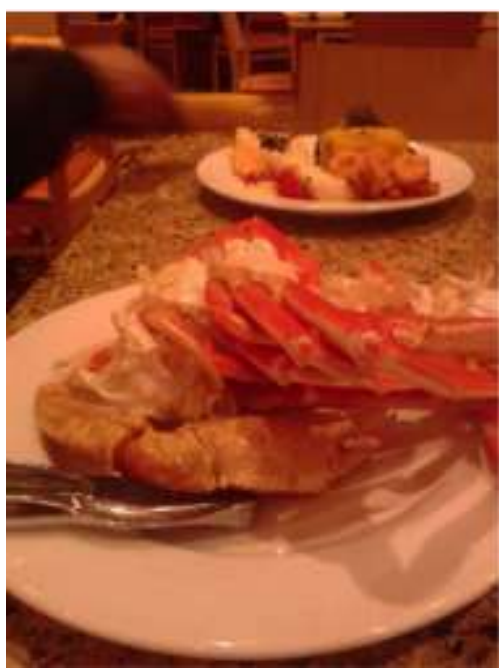

Figure 4: "Buffet." Photo by Maria. 
you have to treat yourself." (Maria, Seattle,

Figure 4)

Pictures are here used as evidence of what the interviewee is saying: they help participants to relate their stories and to let researchers "in" their lives, not only telling them, but also showing them their daily lives. Pictures are used as an enhanced communication channel, and make participants feel they can communicate in a more effective way. On the other hands, researchers have an effective tool to grab participants' reality, which they are not part of, in a more comprehensive way than by relying only on oral methods.

\subsubsection{Interpretation adds representation or meaning to description}

In Seattle, the third most represented category was Add representation or meaning (16\%), slightly differently than in Nogales, where the third category was Add feelings (13\%). This can be explained by the dissimilar situations participants have to face in these two locations.

Participants in Seattle have already reached their destination, so they are somehow in a more stable situation. This does not mean they do not have to face challenges every day. For those who are illegally in the country fear of deportation is constantly present. However, being more established in a place, Seattle, has an influence on their perspectives. Participants' narratives are more likely to evoke memories of what is left behind, coupled with nostalgic feelings, or to find new meanings in their new surroundings.

Here is an example of a photo taken by a participant in Seattle (Juan,) which description adds meanings to his photo:

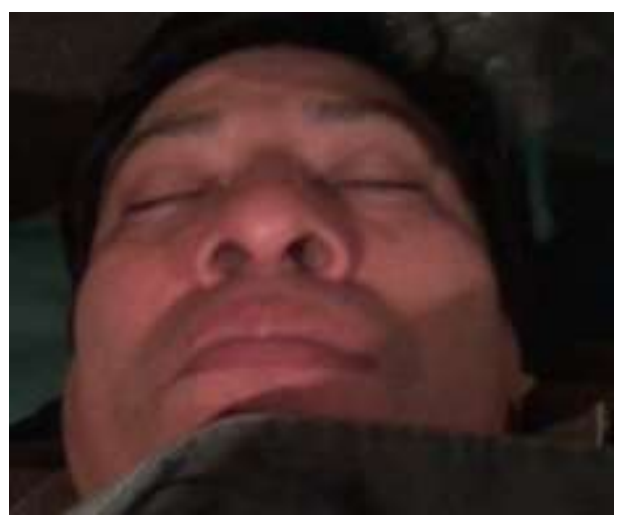

Figure 5: “American Dream.” Photo by Juan.

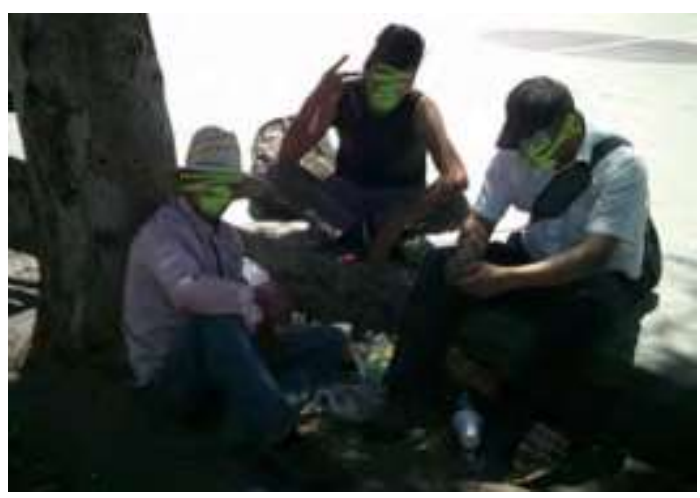

Figure 6: "They look happy.” Photo by Chiapas

"This is my American Dream, for me and for all the Hispanics who are here. You dream about going to the U.S. and you think: "Oh, I will earn dollars and return to Guatemala and buy a nice car, a nice house, buy cows, etc. " So this picture of me sleeping and dreaming about my American Dream of coming here to the U.S. to earn dollars and baskets of money and go back and be rich. And then you get here and it's not like that. Where is the money? Where are all the riches? Where do you pick up the money? It's all lies. The American Dream that everyone is talking about is not like that."(Juan, Seattle, Figure 5)

The photo portrays Juan as sleeping profoundly. This is just the pretext, the starting point for Juan of relating about his dreams and hopes, all framed in the metaphor of the "American Dream".

\subsubsection{Interpretation adds feelings to description}

In Nogales the third most used category was Add feelings (13\%). Participants were in a transitory moment of their lives, living one day at a time while struggling to both survive and cross the border. This kind of situation is more likely to evoke feelings of sorrow and nostalgia, but also hope and gratitude to those who are helping them.

The following example describes the situation portrayed in the picture (see Figure 6). At the same time, though, Chiapas relates and reflects on the internal struggle that he shares with the other migrants, and that he tries to cover by looking happy:

"They look like they are happy, but I know that inside they are worried. Inside you are thinking: How am I going to cross? Will I get there? Will I make it? That's why I took this 
picture: They look like they are happy but I know that inside, each one of us is worried"

(Chiapas, Nogales, Figure 6)

In this short and intense explanation, Chiapas encloses the feelings of being a migrant at the border, at the turning point of their journey, at the border between here and there. Despite trying to enjoy life and engaging in light activities such as playing cards, they are worried for the success of their journey and for their safety. The photo is, again, a pretext to talk about the real point: crossing the border. In this case, it is used to represent a contrast, and not as a symbolic starting point.

\subsection{In relation to $R Q 2$ : How do participants use participatory photography as part of the interview process?}

Technical effects used in the pictures by participants were evaluated in order to find possible how the use of certain elements and effects in the photos could have a role in their interpretation, even if we cannot assume that in all the cases participants used technical effects intentionally. Our analysis reveals that there were some patterns in the use of dark or blurry photos, type of shot, presence of technology devices and pictures of other pictures.

However, variables like gender, age, presence of participants or researches on the photo, did not show patterns in relation with the interpretation provided.

\subsubsection{Dark, blurry or moved photos}

We initially assumed that the lack of quality in some photos (dark, blurry or moved,) was due to the fact that participants wanted to use the images as representations of something else. However, as opposed to our hypothesis, the majority of low quality pictures (see Table 2) were used to express literal interpretation (36\%) and add context (24\%). Add representation or meaning came third (19\%). It is important to clarify that categories were not exclusive; it means that in some cases the participant started its interpretation by describing what was on the photo and

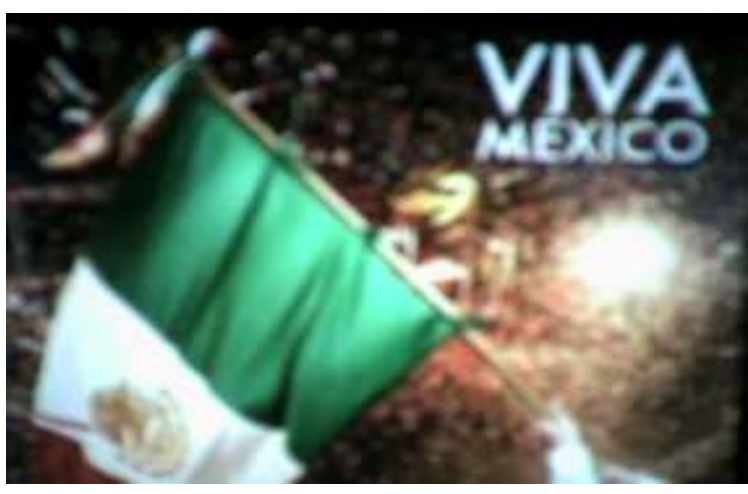

Figure 7: "Viva Mexico." Photo by Lourdes

then expanded it by adding some context, meaning, people or memories.

Here is an example of one of the low quality photos were the participant (Lourdes) starts her interpretation by mentioning what is on the photo and continues adding representation or meaning:

"This is a picture of the flag of my country of
origin." "I carry my flag wherever I go. It has
millions of people who are around it. It contains
all the people from Mexico who live in Seattle.
For me, it is a combination of being proud
where you made it, and also remembering
where your roots are from, remember where
you come from so you never deny the soil that
saw your birth."

\subsubsection{Technology devices}

The presence of technology devices in the photos was another variable we considered in this analysis, even when just $5 \%$ of the photos showcased a piece of technology. The reason is we wanted to find out what was the use participants were giving to the different types of technologies we found in the photos, especially since some of them have low levels of digital literacy. This study revealed that in most of the cases the interpretation of the photo was literal or added context, showing the intentionality behind the presence of the devices, as part of the meaning the

Table 2: Features of the photos in relation to participants' interpretations

\begin{tabular}{lrrr}
\hline Categories & Dark or blurry & Technology devices & \multicolumn{2}{c}{ Picture of a picture } \\
\hline Literal or intrinsic & $36 \%$ & $35 \%$ & $42 \%$ \\
Add context & $24 \%$ & $35 \%$ & $22 \%$ \\
Add feelings & $4 \%$ & $5 \%$ & $5 \%$ \\
Add memories & $9 \%$ & $0 \%$ & $6 \%$ \\
Add people & $6 \%$ & $0 \%$ & $6 \%$ \\
Add representation or meaning & $19 \%$ & $20 \%$ & $19 \%$ \\
Others & $2 \%$ & $5 \%$ & $0 \%$ \\
\hline
\end{tabular}




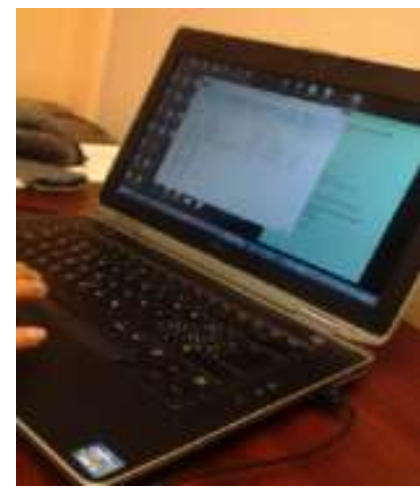

Figure 8: “Laptop.” Photo by Ramón

participant wanted to transmit with the picture. Technology devices were not used to add memories or people.

The following example illustrates how technology devices in images were used in photos with descriptions that were either literal or added context:

This is a picture of a laptop. I have a laptop but it doesn't work anymore. Now I use my phone. I have two cell phones. One has a phone line, and this other one is smartphone but it does not have any phone line. I put a Bluetooth keyboard on it and I use it as a tablet. I watch programs in English, I play games, math games, and I watch things on YouTube, I listen to music. That's how I relax, because if I just stay watching then I get sleepy.

\subsubsection{Picture of a picture}

Although only the $8 \%$ of the photos were pictures of other pictures, we wanted to see if there was an intentionally behind it, and so we found that the interpretation of those photos tended to be literal. When participants used this resource was, in most of the cases, because the existing image contained the meaning they wanted to convey. It also explains why any "pictures of other pictures" were classified as Other (other was used for those images in which description and interpretation did not match).

\subsubsection{Shot type}

As for Shot type, medium shots were used to express literal interpretations, add context, add people, and add feelings. To add memories participants used landscape shots, and to add representation or meaning, as well as for others, participants tended to do close ups. Selfies were considered close ups and were mostly used to add context.

\section{Discussion and Conclusions}

Participants' interpretations of the visual material were mostly either literal (29\%) or added context $(29 \%)$ to the photographs. Feelings $(9 \%)$, memories (8\%) and meaning (13\%) were in general less explicitly cited. This result might be an implication of the participatory nature of the study: by taking their own photos, participants most likely tried to convey their messages and meanings at the visual level already, while taking their photos. When confronted with pictures that researchers bring into the conversation, instead, participants might be more likely to make meaning of them during the conversation, and add more layers of interpretation (and distance, feelings, memories, etc.) only in that moment. Further investigation is needed to explore

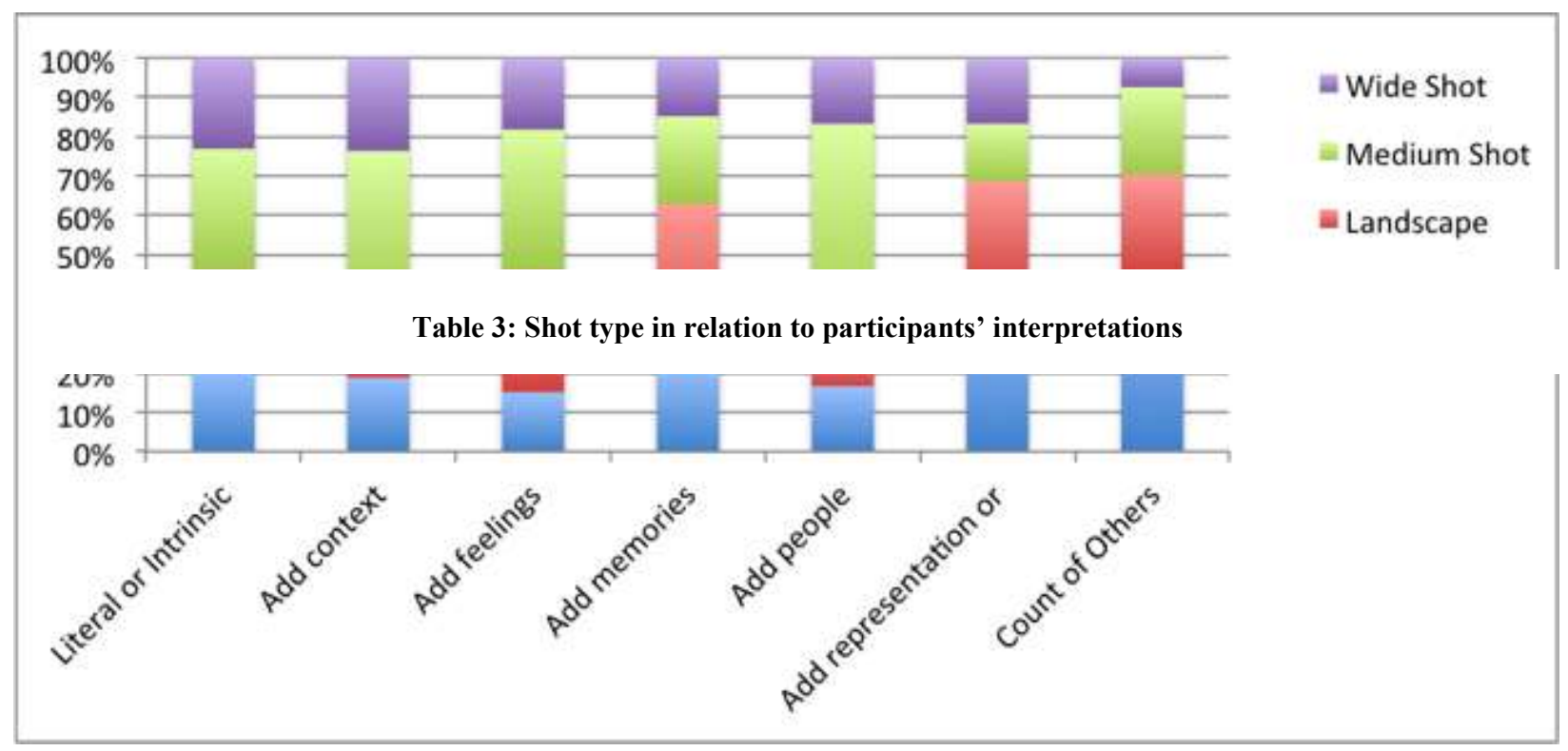


this hypothesis in more detail, and better understand the possibilities and implications of the methodology.

When more meanings and feelings were added to the interpretation of the pictures, however, we see that participants used pictures as evidence to explain their context, as a starting point to explain a more abstract and symbolic concept, or to create a contrast between internal and external struggles they are living. This is in line with previous research analyzing how underserved and technological non-savvy communities use participatory photos in interviews (see: [11]).

Results on the use of effects or elements on the photos also indicate that their use was intended to illustrate the situation participants wanted to express, and not to add feelings or memories. As presented in Table 2, when interpretations reaffirmed or added contextual elements to what was on the image, participants used these elements or effects to add more meaning to their stories, as showed in the "Viva Mexico" example (see Figure 7).

Also, participants used photos as a way to better express and communicate their experiences. This is in line with the purpose of the methodology, thought to empower participants and give them a voice. In Fotohistorias, participants took ownership of the visual images production process, and used it to reflect on their experiences and be empowered.

This meta-analysis of Fotohistorias not only reaffirms scholars' work on how participatory photography can help researchers in eliciting information and obtain better understanding of participants' context. [5], [7], [22] It also provides insights on the participants' world views in profound and unexpected ways, and also offers an opportunity for participants to reflect on the technique itself. Our analysis of the distance between a factual description of an image, and the additional layers of meanings attributed to images by participants, offers a structured way to understand one of the powerful contributions of participatory photography to elicit lived experiences and emic perspectives from the point of view of participants, in ICTD projects as well as other types of projects and settings.

\section{References}

[1] S. Vannini, "Social Representations of Community Multimedia Centres in Mozambique," Doctoral dissertation, Università della Svizzera italiana - USI, Lugano, Switzerland, 2014.

[2] J. Collier, Visual anthropology: photography as a research method. Holt, Rinehart and Winston, 1967.
[3] B. E. Harcourt, Language of the Gun: Youth, Crime, and Public Policy. Chicago, USA: University of Chicago Press, 2006.

[4] L. Blinn and A. W. Harrist, "Combining native instant photography and photo-elicitation," Vis. Anthropol., vol. 4, no. 2, pp. 175-192, 1991.

[5] S. Vannini, I. Rega, S. Sala, and L. Cantoni, "Using Photo-elicitation to Explore Social Representations of Community Multimedia Centres in Mozambique," Electron. J. Inf. Syst. Dev. Ctries., vol. 67, no. 8, 2015.

[6] D. Nemer, Favela Digital: The other side of technology. Vitoria, Brazil: GSA Editora e Grafica, 2013.

[7] S. Vannini, R. Gomez, and V. Guajardo, "Security and Activism: Using participatory photography to elicit perceptions of Information and Authority among Hispanic migrants in the U.S.," presented at the iConference, Philadelphia, PA, USA, 2016.

[8] K. Yefimova, M. Neils, B. C. Newell, and R. Gomez, "Fotohistorias: Participatory Photography as a Methodology to Elicit the Life Experiences of Migrants," presented at the 48th Annual Hawaii International Conference on System Sciences (HICSS), Hawaii, 2015.

[9] P. Sarah, Doing Visual Ethnography. 1 Oliver's Yard, 55 City Road, London England EC1Y 1SP United Kingdom: SAGE Publications, Ltd, 2007.

[10] S. Vannini, L. Aguirre, I. Rega, and L. Cantoni, "Images of Community Multimedia Centres in Mozambique: a participatory photo-elicitation study," in Proceedings of the 12th International Conference on Social Implications of Computers in Developing Countries. Into the Future: Themes, insights and agendas for ICT4D research and practice, Ocho Rios Jamaica, 2013, pp. 348-362.

[11] S. De Ascaniis, S. Vannini, and L. Cantoni, "Argumentation in photo-driven interviews. A Mozambican case in ICT for Development," 2017.

[12] S. Drew and M. Guillemin, "From photographs to findings: visual meaning-making and interpretive engagement in the analysis of participant-generated images," Vis. Stud., vol. 29, no. 1, pp. 54-67, 2014.

[13] L. Pauwels, "Visual Sociology Reframed: An Analytical Synthesis and Discussion of Visual Methods in Social and Cultural Research," Sociol. Methods Res., vol. 38, no. 4, pp. 545581, May 2010.

[14] Using Visual Data in Qualitative Research. 1 Oliver's Yard, 55 City 
Road, London England EC1Y 1SP United Kingdom: SAGE Publications Ltd, 2007.

[15] J. Samuels, “Breaking the Ethnographer's Frames Reflections on the Use of Photo Elicitation in Understanding Sri Lankan Monastic Culture," Am. Behav. Sci., vol. 47, no. 12, pp. 1528-1550, Aug. 2004.

[16] G. Rose, Visual methodologies an introduction to the interpretation of visual materials. Los Angeles; London; New Delhi [etc.]: Sage Publications, 2007.

[17] M. Clark-Ibáñez, "Framing the Social World With Photo-Elicitation Interviews," Am. Behav. Sci., vol. 47, no. 12, pp. 1507-1527, Aug. 2004.

[18] R. Gomez and S. Vannini, Fotohistorias: Participatory Photography and the Experience of Migration. Seattle, WA.: CreateSpace Independent Publishing Platform, 2015.
[19] S. Mazzali Lurati and L. Cantoni, "Photography, semiotics of," in ELL - Encyclopedia of Language \& Linguistics, 2nd ed., vol. 9, K. Brown, Ed. Oxford, UK.: Elsevier, 2005, pp. 569-571.

[20] L. Young and H. Barrett, "Adapting visual methods: action research with Kampala street children," Area, vol. 33, no. 2, pp. 141-152, Jun. 2001.

[21] D. R. Dodman, "Shooting in the city: an autophotographic exploration of the urban environment in Kingston, Jamaica," Area, vol. 35, no. 3, pp. 293-304, Sep. 2003.

[22] R. Gomez and S. Vannini, Fotohistorias: Participatory Photography and the Experience of Migration. Seattle, WA.: CreateSpace Independent Publishing Platform, 2015. 